\title{
Insight into transketolase of Pyropia haitanensis under desiccation stress based on integrative analysis of omics and transformation
}

Jianzhi Shi ${ }^{1,2 \dagger}$, Wenlei Wang ${ }^{1,2 \dagger}$, Yinghui Lin ${ }^{1,2}, K^{1}{ }^{*} X^{1,2}, Y^{*} X^{1,2}$, Dehua $\mathrm{Ji}^{1,2}$, Changsheng Chen ${ }^{1,2}$ and Chaotian $\mathrm{Xie}^{1,2^{*}}$

\begin{abstract}
Background: Pyropia haitanensis, distributes in the intertidal zone, can tolerate water losses exceeding 90\%. However, the mechanisms enabling $P$. haitanensis to survive harsh conditions remain uncharacterized. To elucidate the mechanism underlying $P$. haitanensis desiccation tolerance, we completed an integrated analysis of its transcriptome and proteome as well as transgenic Chlamydomonas reinhardtii carrying a $P$. haitanensis gene.

Results: $P$. haitanensis rapidly adjusted its physiological activities to compensate for water losses up to $60 \%$, after which, photosynthesis, antioxidant systems, chaperones, and cytoskeleton were activated to response to severe desiccation stress. The integrative analysis suggested that transketolase (TKL) was affected by all desiccation treatments. Transgenic C. reinhardtii cells overexpressed PhTKL grew better than the wild-type cells in response to osmotic stress.
\end{abstract}

Conclusion: $P$. haitanensis quickly establishes acclimatory homeostasis regarding its transcriptome and proteome to ensure its thalli can recover after being rehydrated. Additionally, PhTKL is vital for $P$. haitanensis desiccation tolerance. The present data may provide new insights for the breeding of algae and plants exhibiting enhanced desiccation tolerance.

Keywords: Pyropia haitanensis, Desiccation tolerance, Integrative omics analysis, Transketolase, Transgenic experiment

\section{Background}

Pyropia species are commercially valuable marine red algae that have been cultivated for several centuries in East Asia, including in Japan, South Korea and China [1]. The annual production of Pyropia species (many of which were formerly Porphyra species) is currently valued at nearly $\$ 950$ million, with the highest commercial value per unit mass (almost $\$ 523$ per wet metric ton) among all aquaculture seaweed species [2]. These species are widely used as sources of food, fertilizer, medicine, and chemicals [1]. Kellogg and Lila (2013) reported that

\footnotetext{
* Correspondence: ctxie@jmu.edu.cn

†Jianzhi Shi and Wenlei Wang contributed equally to this work.

${ }^{1}$ Fisheries College, Jimei University, Xiamen 361021, China

${ }^{2}$ Key Laboratory of Healthy Mariculture for the East China Sea, Ministry of

Agriculture, Xiamen 361021, China
}

Pyropia species extracts inhibit the generation of oxygen radicals in vitro systems, suggesting that if they are incorporated into the diet, they may have beneficial effects on many oxidative-damage related conditions (e.g. obesity and cardiovascular disease) [3]. Pyropia species may also contribute to the production of "blue carbon" and represent a potentially useful source of biofuel. The expansion of artificial seeding and the development of the floating culture method have considerably enhanced the farming and processing of Pyropia species, which represents one of the largest aquaculture industries. Pyropia haitanensis, originally identified in Fujian Province in China, is a typical warm temperate zone species, and it accounts for $75 \%$ of the total production of Pyropia species in China [4]. 
Pyropia species grow in the intertidal zone, where they encounter fluctuations in several abiotic factors due to the tidal cycle. At low tide, $P$. haitanensis is exposed to air, resulting in $80-95 \%$ water loss [1]. Pyropia species have evolved diverse strategies and mechanisms to withstand such desiccation stress conditions. Consequently, artificially increasing the drying time has been widely used to eliminate wild algae and pathogenic bacteria over the past 50 years, thereby improving the production of Pyropia species (Fig. 1). The underlying strategies that enable intertidal macroalgae to survive harsh conditions have not been fully characterized. Studies on the mechanisms of desiccation tolerance have mainly focused on the role of reactive oxygen species (ROS) and changes to the photosynthetic rate. In $P$. haitanensis, antioxidant enzymes accumulate to scavenge ROS produced in response to desiccation conditions [5]. Investigations of many intertidal macroalgae have revealed that decreasing photosynthesis efficiency is another way to reduce ROS production [6]. Additionally, the accumulation of osmotic solutes is an important part of the response to desiccation stress. For example, the floridoside concentration in $P$. haitanensis reportedly increases to protect cells from damages caused by dehydration [7]. However, the protective mechanisms that allow Pyropia to adapt to desiccation conditions have yet to be fully elucidated.

Recent advances in "omics" technologies have enabled quantitative analyses of the abundance of biological molecules in a high-throughput manner, making it possible

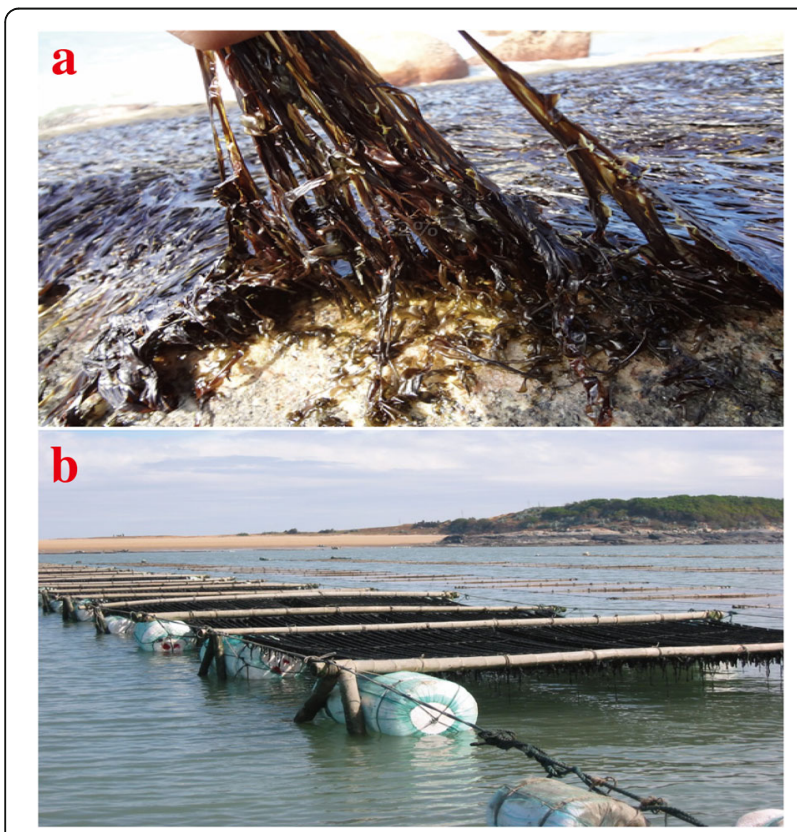

Fig. 1 Wild Pyropia haitanensis exposed to severe desiccation stress conditions at low tide (a). Fishermen regularly use buoys to lift $P$. haitanensis nets above the sea water level to ensure thalli lose water to eliminate wild algae and pathogenic bacteria (b) to elucidate the mechanisms underlying the desiccation tolerance of intertidal seaweeds [8]. Because of a lack of genomic information, transcriptomic and proteomic analyses have recently been widely applied to the study of Pyropia species [9-11]. Wang et al. (2015) analyzed the transcriptome of $P$. haitanensis exposed to desiccation stress, and identified more than 1500 differentially expressed unigenes (DEGs). Additionally, several metabolic pathways were determined to be involved in the desiccation response, such as trehalose biosynthesis, apoptosis induction, and porphyrin and chlorophyll metabolism [12]. In a study of Pyropia orbicularis, 129 proteins were affected by desiccation stress and 56 of these proteins were identified following a bioinformatics analysis. The identified proteins were functionally classified as related to energy and biomolecule metabolism, antioxidant and defense function, and others [13]. $\mathrm{Xu}$ et al. (2016) identified 100 differentially expressed proteins (DEPs) in P. haitanensis under desiccation conditions, which were mainly associated with photosynthesis and energy metabolism [14]. However, these two investigations of the desiccation tolerance of $P$. orbicularis and $P$. haitanensis were conducted based on two-dimensional electrophoresis (2-DE). The disadvantages of 2-DE include the relatively limited coverage and the potential for inaccurate protein quantification. To overcome some of the limitations of gel-based techniques, isobaric tags for relative and absolute quantitation (iTRAQ) has been recently applied to study Pyropia species, thereby improving the throughput and increasing the sensitivity of proteomic studies [15].

The responses of Pyropia species to desiccation conditions are affected not only by desiccationresponsive genes or proteins, but also by interactions among the genes and proteins. The relationship between the transcriptome and proteome has not been characterized in $P$. haitanensis exposed to desiccation stress. Therefore, integrating transcriptomic and proteomic approaches in biological studies is warranted because of the generation of complementary data, which enables a more comprehensive molecular characterization. However, gene functions are normally predicted based on BLAST searches. Although previous studies have examined transformed Pyropia species, they involved transiently transformed and unstable algae [16, 17]. Chlamydomonas reinhardtii was recently described as a good vector for the functional verification of Pyropia species genes [16, 17]. Therefore, in the present study, we used $C$. reinhardtii to comprehensively investigate $P$. haitanensis desiccation tolerance. The main objective of this study was to identify the important genes/proteins or pathways through which this intertidal algal species adapts to desiccation stress. 


\section{Results}

Principal component analysis of Pyropia haitanensis transcriptomic and proteomic data

Details regarding the de novo transcriptome assembly and functional annotations are provided in Additional file 1: Table S3. To assess the correlations among the transcriptomic data, a principal component analysis (PCA) was performed for three replicates per treatment (Fig. 2a). The transcriptomic data were similar for the three replicates per treatment. Moreover, different treatments produced distinct results, suggesting that gene expression levels changed during a prolonged exposure to desiccation stress. Additionally, the iTRAQ-based proteomic analysis of all the $P$. haitanensis samples resulted in 149,413 spectra. After eliminating low-scoring spectra, 30,726 unique spectra that met the strict confidence criteria for identifications were matched to 2676 unique proteins. The PCA of the proteomic data produced results that were similar to those of the transcriptomic data (Fig. 2b).

\section{Expression profiles of differentially expressed genes and proteins}

The unigenes that were up- or down-regulated under desiccation treatments compared to the controls $(0 \%)\left(\log _{2} \mid\right.$ fold change $\mid \geq 1$ and false discovery rate $\leq 0.001$ ) were determined as DEGs. In response to the 30,60 , and $90 \%$ desiccation and rehydration treatments, 276, 794, 526, and 543 unigenes exhibited up-regulated expression, respectively, whereas 287, 628, 519, and 730 unigenes exhibited downregulated expression, respectively (Fig. 3a). The greatest number of DEGs (1422) was detected in the comparison between the 60 and $0 \%$ (control) desiccation treatments. AA Venn diagram analysis of the DEGs under various desiccation stress and rehydration treatments (Fig. 3b) revealed that different genes were responsive to different desiccation conditions, with 267 genes being differentially expressed relative to the control levels in response to all the treatments. A total of 303 DEPs were identified at one or more time-points under desiccation conditions, which represented $11.32 \%$ of all the identified proteins. The number of DEPs generally increased along with the desiccation level, but decreased after the 2-h rehydration step. In response to the 30,60 , and $90 \%$ desiccation and rehydration treatments, the abundances of $36,83,114$, and 17 proteins increased, respectively, while the abundances of $14,60,77$, and 9 proteins decreased, respectively (Fig. 3c). The DEPs were also subjected to a Venn diagram analysis, which revealed that different proteins were responsive to different treatments. Additionally, only one protein was differentially expressed in response to all the treatments (Fig. 3d). Unfortunately, this protein was not functionally annotated.

\section{Functional analyses of differentially expressed genes and proteins}

To obtain a global overview of how $P$. haitanensis responds to desiccation stress, we summarized the changes in gene expression levels according to their putative biological functions. Some important DEGs are listed in Additional file 1: Table S4, including those related to photosynthesis, protein synthesis and degradation, responses to stimuli, the cell wall and cytoskeleton, and energy and carbohydrate metabolism. The functional classification of DEPs (Fig. 4) indicated that most

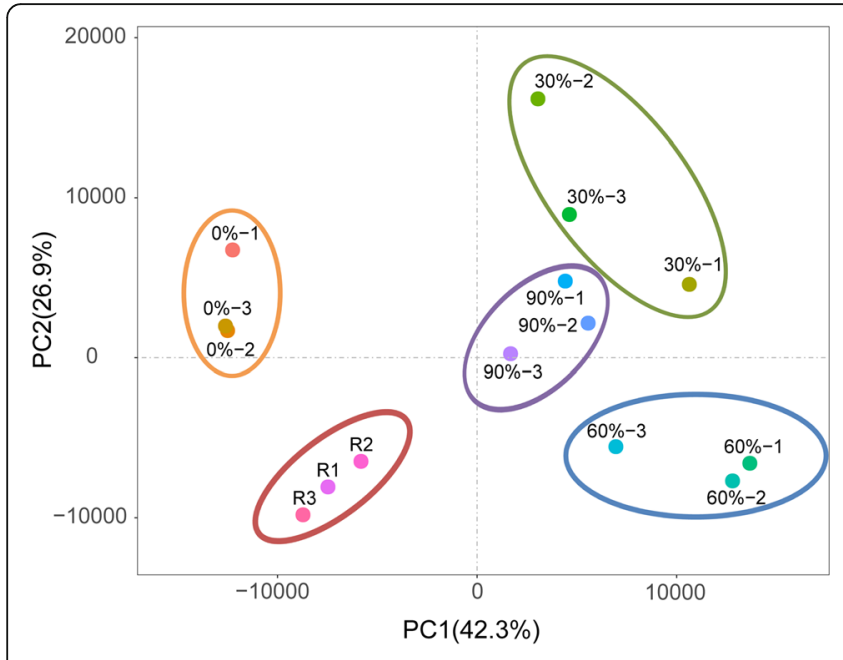

a

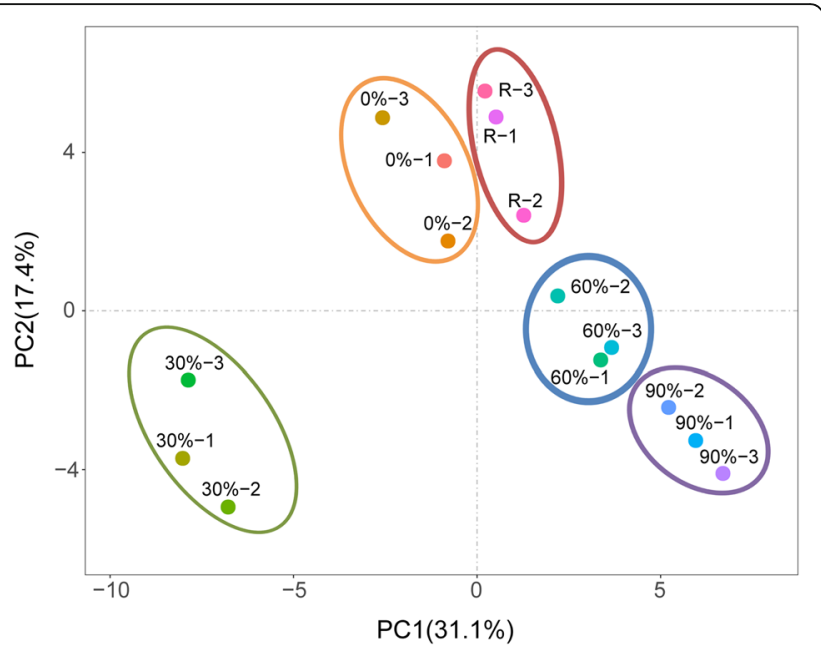

b

Fig. 2 Principal component analysis of Pyropia haitanensis transcriptome (a) and proteome (b) data under desiccation stress. Circles with the same color represent the biological replicates for each treatment. 0\%: control; 30\%: 30\% water loss rate; $60 \%$ : 60\% water loss rate; $90 \%$ : $90 \%$ water loss rate; R: rehydration for $2 \mathrm{~h}$ 

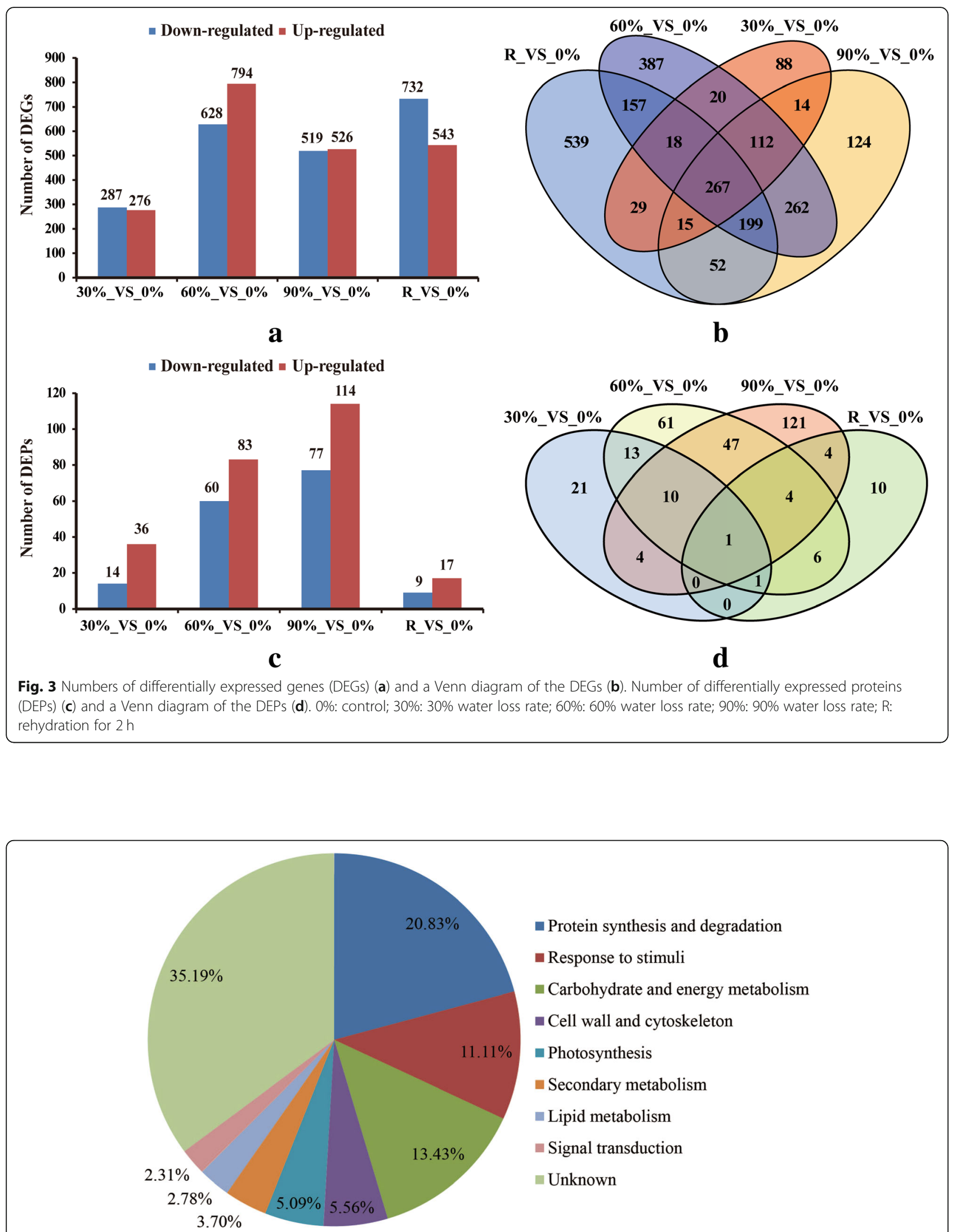

Fig. 4 Functional classification of 216 differentially expressed proteins (DEPs) in Pyropia haitanensis 
(80.56\% of all the DEPs) belonged to one of the following four categories: protein synthesis and degradation (20.83\%), carbohydrate and energy metabolism $(13.43 \%)$, responses to stimuli $(11.11 \%)$, and hypothetical or unknown $(35.19 \%)$. The other categories with DEPs were cell wall and cytoskeleton (5.56\%), photosynthesis (5.09\%), secondary metabolism (3.70\%), lipid metabolism (2.78\%), and signal transduction (2.31\%). A hierarchical cluster analysis grouped the DEPs in response to desiccation stress and rehydration in the following main categories: protein synthesis and degradation, carbohydrate and energy metabolism, responses to stimuli, cell wall and cytoskeleton, and photosynthesis (Fig. 5).
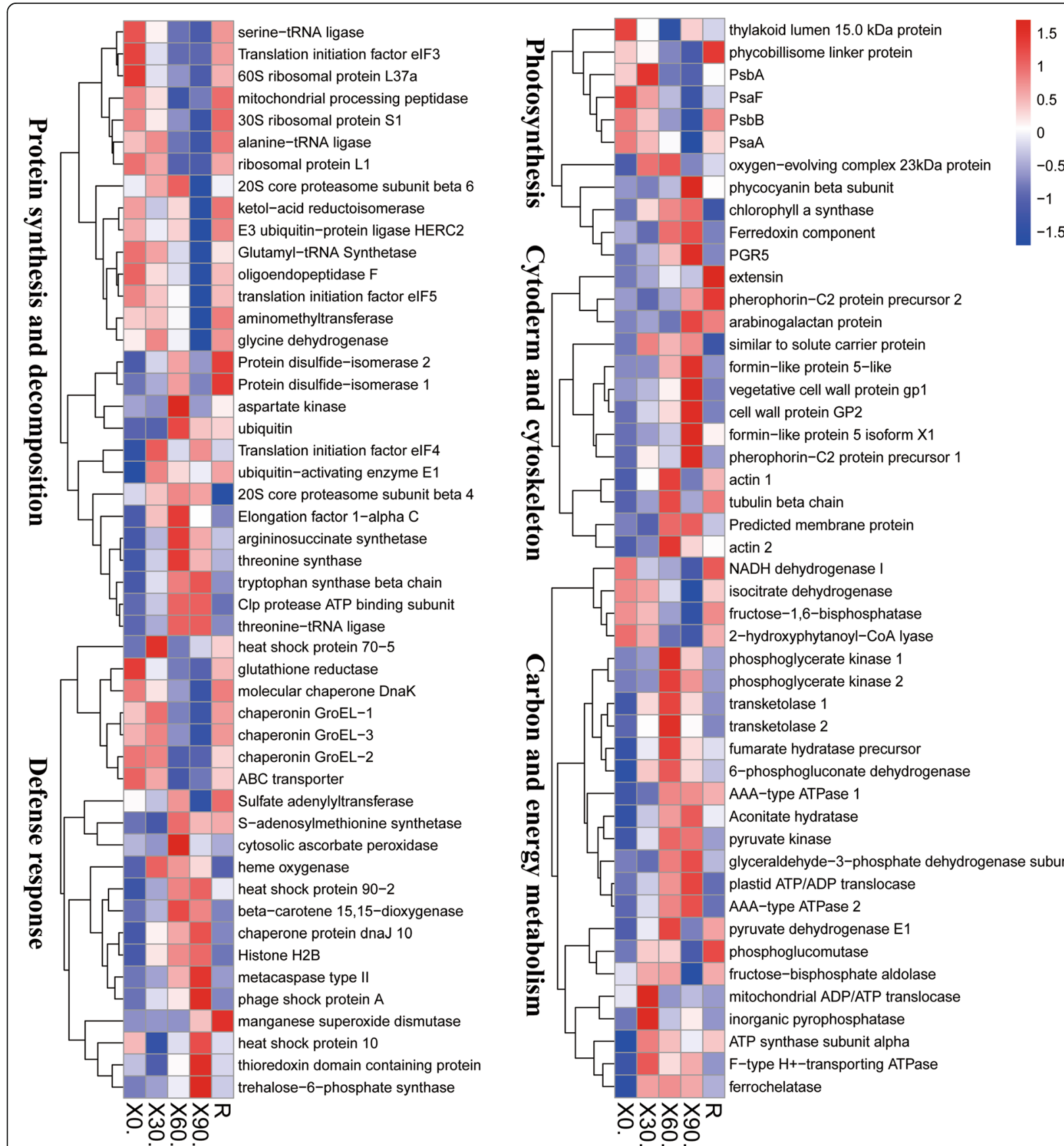

1.5

0.5

0.5

$-1$

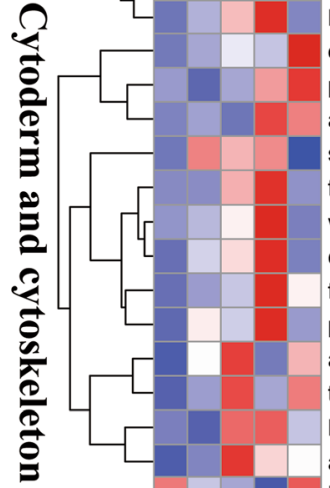

extensin

pherophorin-C2 protein precursor 2

arabinogalactan protein

similar to solute carrier protein

formin-like protein 5-like

vegetative cell wall protein gp1

cell wall protein GP2

formin-like protein 5 isoform $\mathrm{X} 1$

pherophorin-C2 protein precursor 1

actin 1

tubulin beta chain

Predicted membrane protein

actin 2

NADH dehydrogenase I

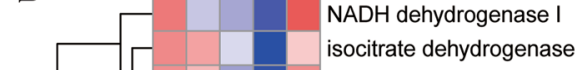

fructose-1,6-bisphosphatase

2-hydroxyphytanoyl-CoA lyase
phosphoglycerate kinase 1
phosphoglycerate kinase 2

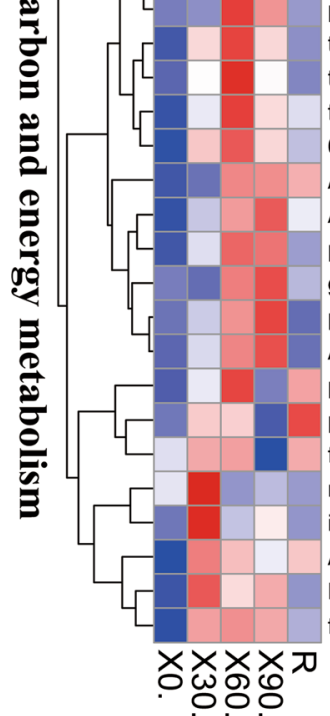

transketolase 1

transketolase 2

fumarate hydratase precursor

6-phosphogluconate dehydrogenase

AAA-type ATPase 1

Aconitate hydratase

pyruvate kinase

glyceraldehyde-3-phosphate dehydrogenase subunit $A$ plastid ATPIADP translocase

AAA-type ATPase 2

pyruvate dehydrogenase $\mathrm{E} 1$

phosphoglucomutase

fructose-bisphosphate aldolase

mitochondrial ADP/ATP translocase

inorganic pyrophosphatase

ATP synthase subunit alpha

F-type $\mathrm{H}+-$ transporting ATPase

ferrochelatase

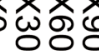

Fig. 5 Hierarchical clustering of differentially expressed proteins (DEPS) in Pyropia haitanensis with similar functions under desiccation conditions and after rehydration. The protein categories were as follows: protein synthesis and degradation, carbohydrate and energy metabolism, responses to stimuli, cell wall and cytoskeleton, and photosynthesis. 0: control; 30: 30\% water loss rate; 60: 60\% water loss rate; 90: $90 \%$ water loss rate; R: rehydration for $2 \mathrm{~h}$ 
Verification of differentially expressed genes and proteins The reliability of the RNA-seq data was assessed by a qRT-PCR assay, in which gene-specific primers were designed for 18 randomly selected genes. There was a good correlation between the transcript abundances based on the qRT-PCR assay and the transcript profile revealed by the RNA-seq data (Additional file 1: Figure S1). In total, 30 DEPs were selected to establish an MRM method, which was developed for 20 DEPs. The expression patterns based on the quantitative data from additional MRM analyses were basically correlated with the expression patterns determined by the iTRAQ data (Fig. 6), implying that the iTRAQ results were reliable.

Integrated analysis of transcriptomic and proteomic data The distribution of the corresponding mRNA:protein ratios was analyzed using scatterplots of the $\log _{2^{-}}$ transformed ratios. Most of the mRNA:protein ratios were concentrated at the center of the plot (quadrant 5), where mRNA and protein levels did not change more than 1.2- and 2-fold, respectively (Additional file 1: Figure S2). Of the 216 identified DEPs, only 48 had corresponding DEGs in the RNA-seq data, which were detected in quadrants $1,3,7$, and 9. A subsequent analysis was completed with the red scatterplots in quadrants 3 and 7, which indicated that the expression level changes were consistent between the DEGs and corresponding DEPs. A total of 26 DEGs were identified (Table 1). Moreover, the up-regulated DEGs were associated with specific activities (e.g., pentose phosphate pathway, ROS scavenging, inositol metabolism, Calvin cycle, photosynthetic electron transport, glycolysis, and cell wall modification). In contrast, the down-regulated DEGs were related to molecular chaperone, protein

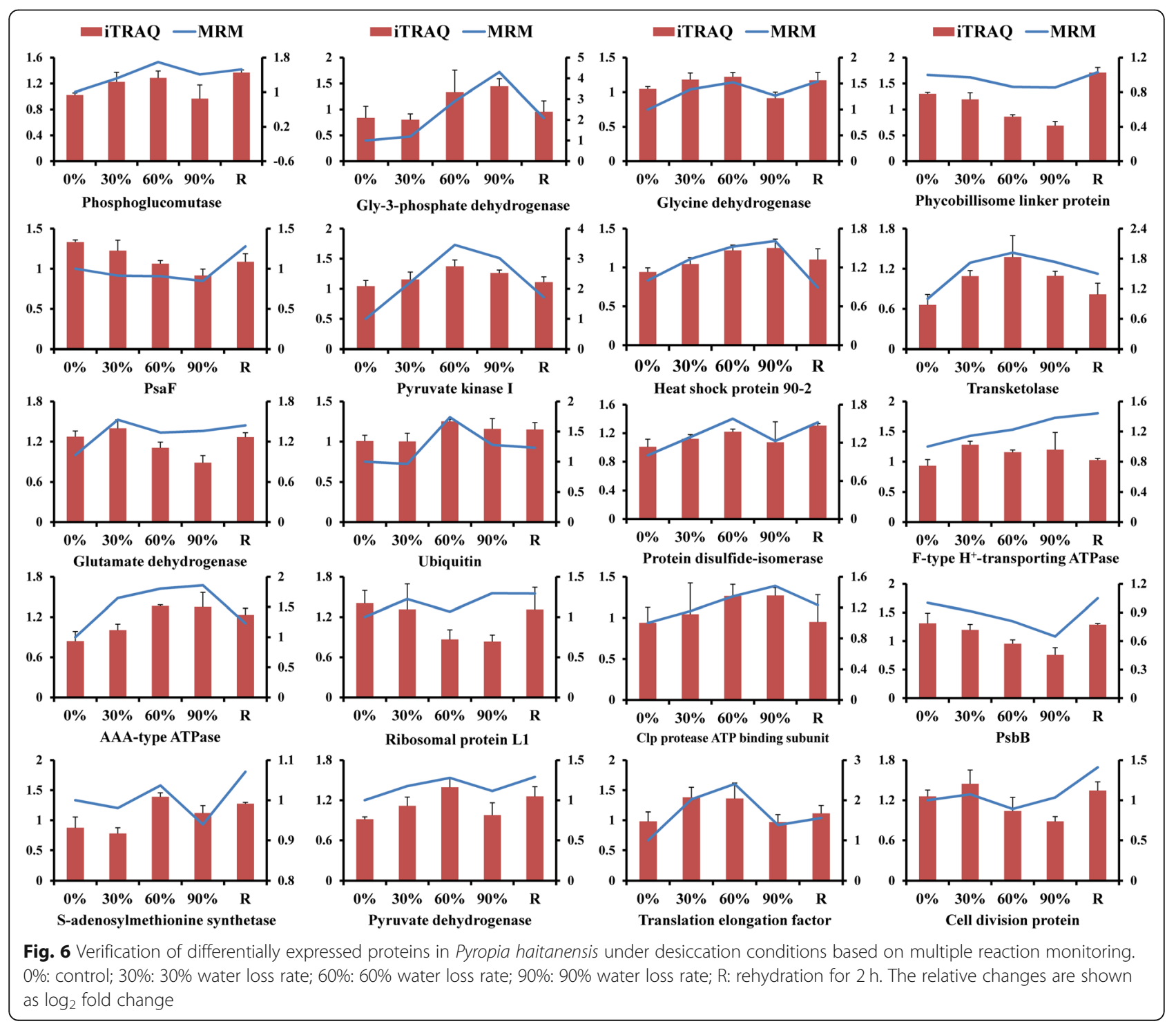


Table 1 Differentially expressed genes that changed in accordance with their homologous differentially expressed proteins

\begin{tabular}{|c|c|c|c|c|}
\hline Gene ID & $\left(\log _{2} F C\right)$ & $\begin{array}{l}\text { Proteins } \\
\left(\log _{2} \text { FC) }\right.\end{array}$ & Annotation & Function \\
\hline \multicolumn{5}{|l|}{$30 \% \_V S \_0 \%$} \\
\hline c12879_g1 & 2.13 & 0.72 & Transketolase & Pentose phosphate pathway \\
\hline c10632_g1 & 4.83 & 0.32 & Hypothetical protein & Hypothetical or unknown \\
\hline c13641_g2 & 2.09 & 0.39 & Heme oxygenase & ROS scavenging \\
\hline \multicolumn{5}{|l|}{$60 \%$ VS_0\% } \\
\hline c12879_g1 & 5.40 & 1.06 & Transketolase & Pentose phosphate pathway \\
\hline c13777_g1 & 4.50 & 0.53 & Myo-inositol dehydrogenase & Inositol metabolism \\
\hline c12790_g1 & 4.28 & 0.71 & Phosphoribulokinase & Calvin cycle \\
\hline c10632_g1 & 8.22 & 0.38 & Hypothetical protein & Hypothetical or unknown \\
\hline c13780_g20 & 1.46 & 0.50 & Glycosyl transferase & Secondary metabolism \\
\hline c12732_g3 & 3.09 & 0.84 & Proton Gradient Regulation 5 & $\begin{array}{l}\text { Photosynthetic electron } \\
\text { transport }\end{array}$ \\
\hline c24990_g1 & 2.43 & 0.53 & Unnamed protein product & Hypothetical or unknown \\
\hline c10780_g1 & 1.42 & 0.72 & Ferredoxin & $\begin{array}{l}\text { Photosynthetic electron } \\
\text { transport }\end{array}$ \\
\hline c13180_g3 & -2.24 & -0.27 & Molecular chaperone DnaK & Molecular chaperone \\
\hline c11346_g1 & -1.00 & -0.57 & Chaperonin GroEL & Molecular chaperone \\
\hline c1535_g1 & -2.46 & -0.51 & Unnamed protein product & Hypothetical or unknown \\
\hline c9789_g1 & -1.13 & -0.43 & Putative protein disulfide-isomerase & Protein processing \\
\hline c13728_g2 & -1.95 & -0.86 & Hypothetical protein & Hypothetical or unknown \\
\hline c12496_g2 & -3.06 & -0.37 & $\begin{array}{l}\text { Pyrophosphate--fructose 6-phosphate } \\
\text { 1-phosphotransferase }\end{array}$ & Carbon metabolism \\
\hline \multicolumn{5}{|l|}{ 90\%_VS_0\% } \\
\hline C12879_g1 & 3.73 & 0.73 & Transketolase & Pentose phosphate pathway \\
\hline c13133_g2 & 3.87 & 0.35 & Predicted protein & Hypothetical or unknown \\
\hline c13777_g1 & 3.26 & 0.62 & Myo-inositol dehydrogenase & Inositol metabolism \\
\hline c13015_g1 & 1.06 & 0.47 & Probable dehydrogenase & Hypothetical or unknown \\
\hline c11143_g1 & 3.12 & 0.79 & $\begin{array}{l}\text { Glyceraldehyde-3-phosphate } \\
\text { dehydrogenase }\end{array}$ & Glycolysis \\
\hline c12940_g1 & 1.21 & 0.51 & Unnamed protein product & Hypothetical or unknown \\
\hline c14325_g1 & 1.27 & 0.39 & Ferrochelatase & Secondary metabolism \\
\hline c13026_g1 & 1.01 & 0.62 & Unnamed protein product & Hypothetical or unknown \\
\hline c11214_g2 & 1.42 & 0.50 & Unnamed protein product & Hypothetical or unknown \\
\hline c12732_g3 & 1.64 & 1.30 & Proton Gradient Regulation 5 & $\begin{array}{l}\text { Photosynthetic electron } \\
\text { transport }\end{array}$ \\
\hline c6671_g1 & 3.80 & 0.66 & Vegetative cell wall protein & Cell wall modification \\
\hline c13180_g3 & -1.98 & -0.43 & Molecular chaperone DnaK & Molecular chaperone \\
\hline c12337_g1 & -1.47 & -0.54 & Photosystem I subunit III & Photosynthesis \\
\hline \multicolumn{5}{|c|}{ Rehydration_VS_0\% } \\
\hline c10380_g1 & 4.78 & 0.37 & Pherophorin-C2 protein & Cell wall modification \\
\hline c12790_g1 & 1.14 & 0.55 & Phosphoribulokinase & Calvin cycle \\
\hline c12337_g1 & -3.33 & -0.29 & Photosystem I subunit III & Photosynthesis \\
\hline c13612_g4 & -3.97 & -0.44 & Uncharacterized protein & Hypothetical or unknown \\
\hline
\end{tabular}


processing, and photosynthesis. Both transketolase genes and encoded proteins were upregulated under 30, 60 and $90 \%$ desiccation conditions (Table 1). A phylogenetic tree supported the existence of a sister-group relationship between $P$. haitanensis and other Rhodophyta species, but implied that Pyropia species diverged from Cyanophyta, Chlorophyta, Phaeophyta, and land plants (Fig. 7).

\section{PhTKL enhances the osmotic tolerance of transgenic Chlamydomonas reinhardtii}

Putative $C$. reinhardtii transformants detected based on their resistance to hygromycin were assessed by PCR with PhTKL-specific primers (Additional file 1: Table S2). The expected PCR products were generated for all the randomly selected hygromycin-resistant lines, but not for the wild-type plants, verifying the integration of PhTKL into the genome of the hygromycin-resistant lines (Additional file 1: Figure S3). The first transgenic lines $\left(T_{1}\right)$ underwent transcriptional and morphological analyses to assess their osmotic tolerance. Specifically, a qRT-PCR assay was completed to determine PhTKL expression levels induced by osmotic stress. PhTKL expression was up-regulated by osmotic stress, with peak levels observed at $6 \mathrm{~h}$ after treatments (Fig. 8a). To functionally characterize PhTKL, C. reinhardtii cells over-expressing PhTKL were cultivated in TAP medium containing $200 \mathrm{mM}$ mannitol. The wildtype and transformed $C$. reinhardtii cells initially grew similarly, but the growth rate of the transgenic cells was obviously greater after 2 days (Fig. 8b).

\section{Discussion}

In this study, we found that $P$. haitanensis rapidly regulated its physiological activities in response to desiccation stress before losing $60 \%$ of its cellular water. A prolonged exposure to desiccation conditions stimulates a series of protective responses, but $P$. haitanensis may also rapidly establish acclimatory homeostasis in its transcriptome and proteome to ensure recovery after being immersed in seawater. We identified 2283 DEGs and 303 DEPs, but only 26 DEGs exhibited expression-level changes that were consistent with the changes in the abundance of the corresponding DEPs. The poor correlation between transcriptomic and proteomic data was likely due to post-transcriptional regulatory activities under desiccation conditions. These findings emphasize the need to investigate molecular processes at transcriptional and translational levels. Such an integrated analysis unveiled a set of stress-inducible genes/proteins, but also revealed the molecular mechanism associated with $P$. haitanensis desiccation tolerance.

\section{Photosynthesis}

The absorption of light is the initial step of photosynthesis. Phycobilisomes, which consists of phycobiliproteins (PBPs) and linker polypeptides, are the major light-harvesting complexes in Pyropia species [15]. On the basis of their

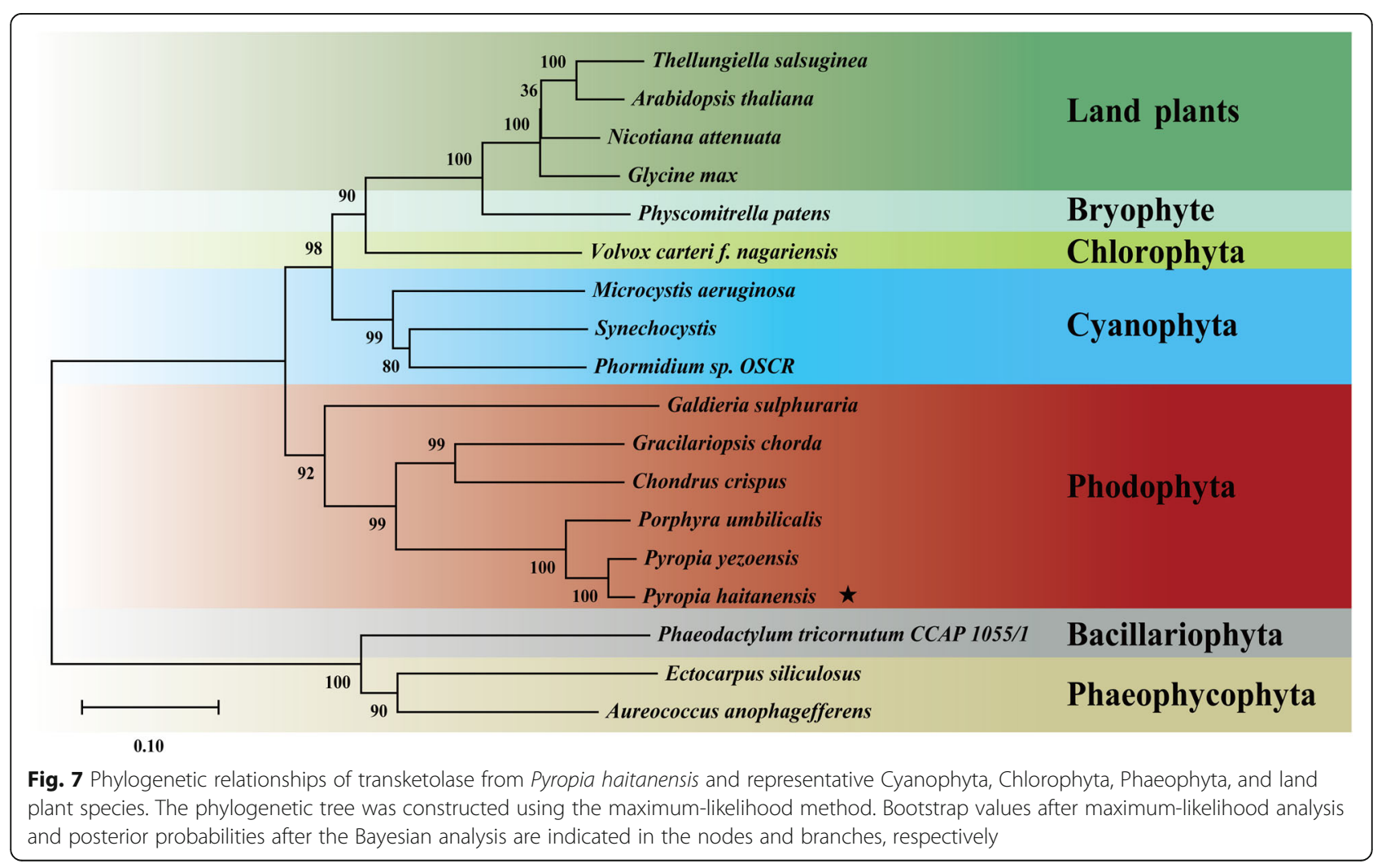




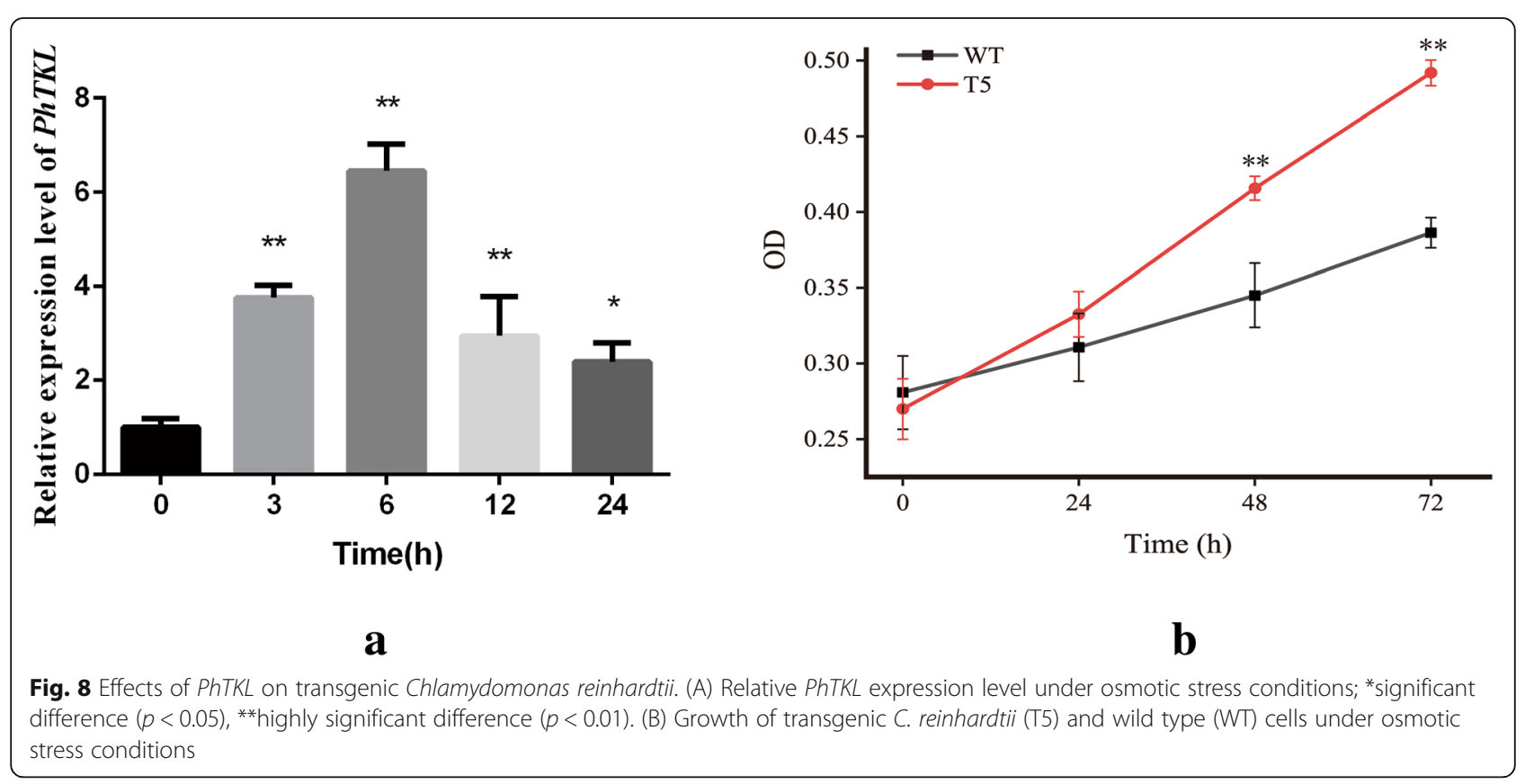

spectral properties and pigment compositions, PBPs can be divided into three main groups, namely phycoerythrin, phycocyanin, and allophycocyanin. In addition to the upregulation of genes related to PBPs, we observed an elevated phycocyanin production in $P$. haitanensis exposed to desiccation stress (Table 1, Fig. 5). This phenomenon was also observed in P. orbicularis, which is distributed along the upper rocky intertidal zone of the Chilean coast [13]. An integrated analysis of the transcriptome and proteome revealed down-regulated DEGs or DEPs related to photosynthesis (Table 1). The increased abundance levels of PBPs may capture light energy and further decrease ROS production. In this study, the $P s b A, P s b B$, and PsaA transcripts and encoded protein levels were maintained under mild desiccation conditions (30\% water loss) and decreased under moderate desiccation conditions (60\% water loss), but could subsequently recover to their original levels (Fig. 5). Similar results were obtained for an examination of $P$. haitanensis photosynthetic parameters, which indicated that the maximum and effective photochemical quantum yields of photosystems II (PSII) were strongly inhibited when the water loss exceeded 60\%; however, they recovered to 79 and $60 \%$ of their original levels, respectively, in the absence of desiccation stress [14]. Thus, $P$. haitanensis may have evolved to accommodate periodic dehydration and rehydration cycles.

The physical properties of the photosynthetic apparatus are important for drought-tolerant plants. Photosynthetic components are very sensitive and prone to damage, and they must be maintained or repaired quickly after rehydration. To prevent the accumulation of photodamaged PSII, the repair process includes assembly of the oxygen-evolving machinery [18]. In the present study, a $23 \mathrm{kD}$ oxygenevolving complex protein was upregulated under moderate desiccation stress (Fig. 5). It has the function to stabilize the $\mathrm{Mn}_{4} \mathrm{CaO}_{4}$ cluster [19]. Desiccation stress usually damages the oxygen-evolving complex of PS II [20, 21]. In contrast, in the current study, its abundance in dehydrated Pyropia thalli may help to maintain the structure of oxygenevolving complex during moderate desiccation conditions, which may influence Pyropia species' responses to desiccation stress. Additionally, the energy transfer to the reaction centers of PS II and PS I lead to electron transfer to ferredoxin and then the reduction of $\mathrm{NADP}^{+}$to NADPH. $\mathrm{NADP}^{+}$is a major acceptor of electrons in PS I [22]. In the current study, ferredoxin was upregulated under severe desiccation stress (Fig. 5), indicating that it might function to promote the reduction of $\mathrm{NADP}^{+}$to $\mathrm{NADPH}$, decrease the transport of electrons from PSI to molecular oxygen and inhibit ROS producion [22]. The accumulation of NADPH in P. haitanensis provides electrons for $\mathrm{P} 700+$ and drives the cyclic electron flow via PSI under severe desiccation conditions (84\% water loss) and recovery during rehydration, while the PS II activity was abolished at a $76 \%$ water loss [23]. This indicated that the cyclic electron flow around PSI was still active after the inactivation of the linear electron flow under severe desiccation conditions. Similarly, the PS I-driven cyclic electron flow of the desiccated P. yezoensis thalli at a $87 \%$ water loss could be rapidly restored upon re-hydration, which was faster than PS II [24]. Furthermore, PROTON GRADIENT REGULATION5 (PGR5) has been suggested to mediate electron transfer via the ferredoxinmediated cyclic electron flow [25]. PGR5 dependent regulation of electron transfer and proton motive force are 
significant for the protection of PS I against photodamage [26]. Mature Arabidopsis overexpressing PGR5 survive exposure to high light and desiccation stress better than wildtype [27]. Here, we also found that PGR5 genes and encoded proteins were upregulated during severe desiccation condition (Fig. 5, Table 1). These results suggest that the cyclic electron flow around PS I might play a significant physiological role in response to desiccation and rehydration, and may be an important factor enabling Pyropia to adapt to intertidal environments.

\section{Cell wall and cytoskeleton}

Cell wall modifications are important for plant acclimations to environmental stresses [28]. In Ulva compressa, cell walls structural changes provide protection from mechanical damage during periodic desiccation-rehydration cycles, thereby enabling this species to adapt to the intertidal zone [29]. Herburger et al. (2019) reported that the accumulation of pectin homogalacturonan in the filament cell wall of Zygnema resulted in increased desiccation tolerance [30]. Under desiccation conditions, P. haitanensis cells shrink, which is similar to the effects of desiccation on other algae cells [7]. Our data also revealed the increased abundance of glycoproteins associated with cell wall modifications (i.e., extensin, pherophorin- $\mathrm{C} 2$ protein, arabinogalactan protein, and cell wall protein) (Fig. 5). Salt stress induces an increase in expansin levels in $P$. haitanensis, which enhances the retention of water [31]. These changes might increase cell wall flexibility and help $P$. haitanensis adjust to environmental conditions. The production of a membrane protein was also induced by desiccation (Fig. 5). Membrane proteins functioning as receptor-like kinases are believed to perceive changes in the extracellular space and transmit their signals into the cell [32]. The expression levels of many genes encoding receptor-like kinases are induced by abiotic stresses, thereby amplifying the signals for necessary stress-adaptive responses, including the maintenance of cell wall integrity [33]. These results highlight the cell wall changes that enable $P$. haitanensis to adapt to desiccation conditions.

The cytoskeleton is a highly dynamic cell component that mainly comprises microtubules and actin filaments. The cytoskeleton of plant cells can undergo substantial changes when subjected to abiotic stresses [34]. The degradation of cytoskeletal proteins might result in cytoskeletal disassembly as well as cell structure changes in Physcomitrella patens under desiccation stress [35]. The actin microfilaments of the green algal species Klebsormidium crenulatum are obviously disrupted in response to desiccation, possibly because of changes to the actin microfilament phosphorylation status [36]. The destruction of the cytoskeleton might be a consequence of desiccation stress among higher plants and green algae [37]. However, recent studies have uncovered a close relationship between the cytoskeleton and abiotic stress tolerance in Pyropia species [13, 15]. The abundance of three actin and tubulin proteins in $P$. haitanensis increased at a WL rate of 60\% (Fig. 5). Actin abundance also increases in the aquatic bryophyte Fontinalis antipyretica Hedw under dehydration conditions, and increases in $\beta$-tubulin contents may help preserve cell structures in F.antipyretica after rehydration [34]. The results of the current study suggest that the cytoskeleton affects the cellular homeostasis of $P$. haitanensis under desiccation conditions. However, the associated mechanisms underlying the desiccation tolerance of Pyropia species will need to be characterized in future studies.

\section{Osmotic adjustment}

Trehalose is a non-reducing disaccharide of glucose that functions as a compatible solute that helps stabilize biological structures under abiotic stress [38]. The abundance of trehalose-6-phosphate synthase (TPS), which catalyzes the synthesis of trehalose, began to increase in response to the $60 \%$ desiccation treatment (Fig. 5). This result was consistent with the findings that TPS expression levels increase in response to considerable water losses [39]. In Selaginella lepidophylla under dehydration conditions, trehalose accumulates to $12 \%$ of the plant dry weight and protects proteins and membrane structures [40]. Additionally, TPS is reportedly overexpressed in $P$. orbicularis under desiccation conditions [41]. The $P$. haitanensis thalli may positively adjust the osmotic potential via the considerable synthesis of trehalose and other osmolytes to adapt to short-term $100 \%$ hypersaline stress [31]. Thus, trehalose appears to be an important osmoprotectant in P. haitanensis.

\section{Protein synthesis and degradation}

Abiotic stress is associated with an enhanced risk of improper protein folding and denaturation [38]. In the current study, desiccation stress decreased the expression levels of genes and abundances of proteins related to protein synthesis, including a ribosomal protein, translation initiation factor, and aminoacyl-tRNA synthetase (Table 1, Fig. 5). High-temperature stress can also repress the synthesis of $P$. haitanensis proteins [15]. These changes may decrease the overall production of proteins, and consequently eliminate some misfolding and denaturation. Nevertheless, misfolded proteins inevitably accumulate in cells under abiotic stress conditions, which necessitate ubiquitination to target proteins for degradation by a proteasome [42]. Our results indicated that the expression levels of genes related to protein degradation decreased during desiccation treatments (Table 1), but the abundance of the corresponding proteins increased (Fig. 5). In an earlier investigation of Ulva prolifera, it was observed that the abundance of DEPs may significantly increase or decrease without a change in 
the corresponding mRNAs levels [43]. Differences between the DEGs and DEPs imply that changes in protein profiles owing to desiccation stress may be controlled at the posttranscriptional level. Moreover, the increased abundances of DEPs linked to ubiquitination may help $P$. haitanensis to remove misfolded proteins and decrease the risk of cell damage. In addition, our data clearly indicated that the abundance of DEPs in this pathway were significantly affected in cells with $60 \%$ water loss (Fig. 5), which is similar to the photosynthesis-related DEPs. These observations are further evidence that the 60\% WL rate is an important threshold for $P$. haitanensis responses to desiccation.

In addition to ubiquitination, chaperone activities may also control the accumulation of misfolded proteins induced by abiotic stress in P. haitanensis [9, 44, 45]. For example, Hsps are common chaperones that maintain functional protein conformations under abiotic stress conditions by preventing nonnative protein aggregations and by refolding proteins into native conformations [46]. Previous 2-DE investigations concluded that Hsps were highly abundant in Pyropia exposed to desiccation stress $[13,14]$. In contrast to the transcriptome results, Hsp70, Hsp90, DnaJ, and Hsp10 abundances increased (Fig. 5), which highlights the post-transcriptional regulation occurring in P. haitanensis. Moreover, decreasing proteins production (Table 1) is an efficient strategy for avoiding protein misfolding and denaturation in $P$. haitanensis [15]. This may explain any decreases in molecular chaperone levels and protein processing activities. The expression patterns of these DEGs imply that $P$. haitanensis blades may limit damages caused by desiccation to repairable levels.

\section{Response to stimuli}

One of the mechanism underlying desiccation-tolerant plants involves the activation of several processes that minimize damage associated with specific by-products (e.g., ROS) [47-49]. In an earlier investigation of Zygnema circumcarinatum, the expression levels of genes encoding glutathione-S-transferase, peroxisomal catalase, peptide methionine sulfoxide reductase and peroxiredoxin were higher in Group P2 than Group L, indicating a more severe ROS stress response in $Z$. circumcarinatum filaments grown on agar plates (desiccation stress) than grown in liquid culture [50]. In various intertidal species, desiccation also significantly enhances ROS production, leading to an increase in antioxidant contents, including enzymes $[5,6]$. In this study, the abundances of ascorbate peroxidase, heme oxygenase, manganese superoxide dismutase, and thioredoxin increased under high $(\geq 60 \%)$ desiccation stress conditions (Fig. 5). In P. haitanensis, an antioxidant system scavenges for redundant ROS to maintain a certain redox balance during short-term $110 \%$ hypersaline stress [27].
The expression levels of PhSOD, PhCSD1 and PhCSD2, were highly induced by the $\mathrm{O}_{2} \cdot{ }^{-}$content in $P$. haitanensis under desiccation and high-temperature stress [51]. Low ROS production and high enzymes activities and antioxidant contents have been revealed during the responses of intertidal seaweed to desiccation stress [6]. Thus, $P$. haitanensis appears to deploy detoxifying enzymes and proteins to control the ROS level, and an antioxidant system likely enhances the survival of blades under desiccation conditions. Furthermore, programmed cell death is crucial for plant development and defense mechanisms [52]. In the current study, we detected an increase in metacaspase abundance (Fig. 6), which is consistent with a previous analysis of $P$. haitanensis responses to high-temperature stress [15]. Consequently, programmed cell death is an important part of $P$. haitanensis defense responses.

\section{Carbohydrate and energy metabolism}

In response to stresses, plants initiate a series of events linked to carbohydrate and energy metabolism [53]. A previous 2-DE study revealed that $P$. haitanensis increases the production of energy-related proteins to withstand desiccation conditions [14]. Our iTRAQ results presented herein confirmed that proteins mediating carbohydrate and energy metabolism are needed for desiccation tolerance, including 29 DEPs related to glycolysis, the tricarboxylic acid (TCA) cycle, and pentose phosphate pathway (Fig. 5). Glycolysis is a central metabolic pathway that provides energy and generates precursors for the synthesis of primary metabolites [54]. Our transcriptome analysis indicated that most DEGs participating in glycolysis exhibited up-regulated expression (Table 1). Similarly, the abundances of all the glycolysis-related DEPs increased following the desiccation treatment (Fig. 5). Respiratory activities proceed along with the mitochondrial reactions of the TCA cycle, ultimately generating large amounts of ATP [55]. The abundances of pyruvate dehydrogenase, aconitate hydratase, and fumarate hydratase, which belong to this pathway, increased under desiccation stress (Fig. 5). Additionally, the pentose phosphate pathway also contributes to the production of energy and sugar phosphates under abiotic stress conditions [56]. Environmental stresses cause Pyropia species to increase their glycolytic activities and induce the TCA cycle [13, 15]. These observations suggest that energy metabolism is a complex process, and that $P$. haitanensis blades require considerable energy to tolerate desiccation stress conditions.

ATKL, which is crucial for the pentose phosphate pathway, was detected in response to all the desiccation treatments (Table 1). TKL generates NADPH and sugar phosphate intermediates [57]. As a multi-functional 
pathway, the pentose phosphate pathway is closely associated with stress tolerance. In $U$. prolifera, NADPH derived from the pentose phosphate pathway provides electrons for the cyclic electron flow around PSI, which enhances the survival of thalli exposed to salt stress [58]. The observed increases in ferredoxin and PGR5 levels imply a similar role under desiccation conditions. Intermediates of the pentose phosphate pathway, such as fructose 6-phosphate and glyceraldehyde 3-phosphate, are also involved in glycolysis [47]. Our data indicate that glyceraldehyde-3-phosphate dehydrogenase production in P. haitanensis was induced by desiccation stress, suggesting that the pentose phosphate pathway regulates the glycolysis pathway. In addition to providing reducing equivalents and energy, the pentose phosphate pathway has been linked to the Calvin cycle via phosphoribulokinase [59]. In this study, phosphoribulokinase production increased under mild and moderate desiccation conditions, implying that the $P$. haitanensis Calvin cycle is maintained for the accumulation of carbohydrates. Glycosyltransferase helps synthesize hemicellulose, pectin, mannans, and various glycoproteins, making it critical for plant cell wall metabolism [60]. Additionally, inositol is a sugar-like carbohydrate produced by most plants, and it regulates cellular water pressure and exhibites antioxidant capacities [61]. Regarding ROS scavenging, heme oxygenase helps protect cells from oxidative damage [62]. On the basis of these results, we speculated that the pentose phosphate pathway indirectly affects the antioxidant activities of $P$. haitanensis. Moreover, Gao et al. (2013) reported that in $P$. haitanensis, the cyclic electron flow rate around PSI increases under desiccation conditions, whereas the linear electron flow around PSII is suppressed. The PSI-driven cyclic electron flow may be more rapidly restored than PSII activities following rehydration, possibly in part because of the enhanced cyclic electron flow around PSI due to the NADPH derived from the pentose phosphate pathway [23]. We functionally characterized PhTKL based on the results of our integrated analysis. We observed that PhTKL expression was induced by osmotic stress (Fig. 8a). Moreover, transgenic C. reinhardtii over-expressing PhTKL grew better than control cells on TAP medium containing a high mannitol concentration (Fig. 8b). Therefore, this is the first report describing the importance of PhTKL for desiccation tolerance (Fig. 9). Furthermore, a phylogenetic tree including PhTKL suggested that Pyropia species diverged from Cyanophyta, Chlorophyta, Phaeophyta, and land plant species (Fig. 7). The specific regulatory mechanism associated with PhTKL will need to be characterized in future studies, which may provide new insights into the stress tolerance of P. haitanensis.

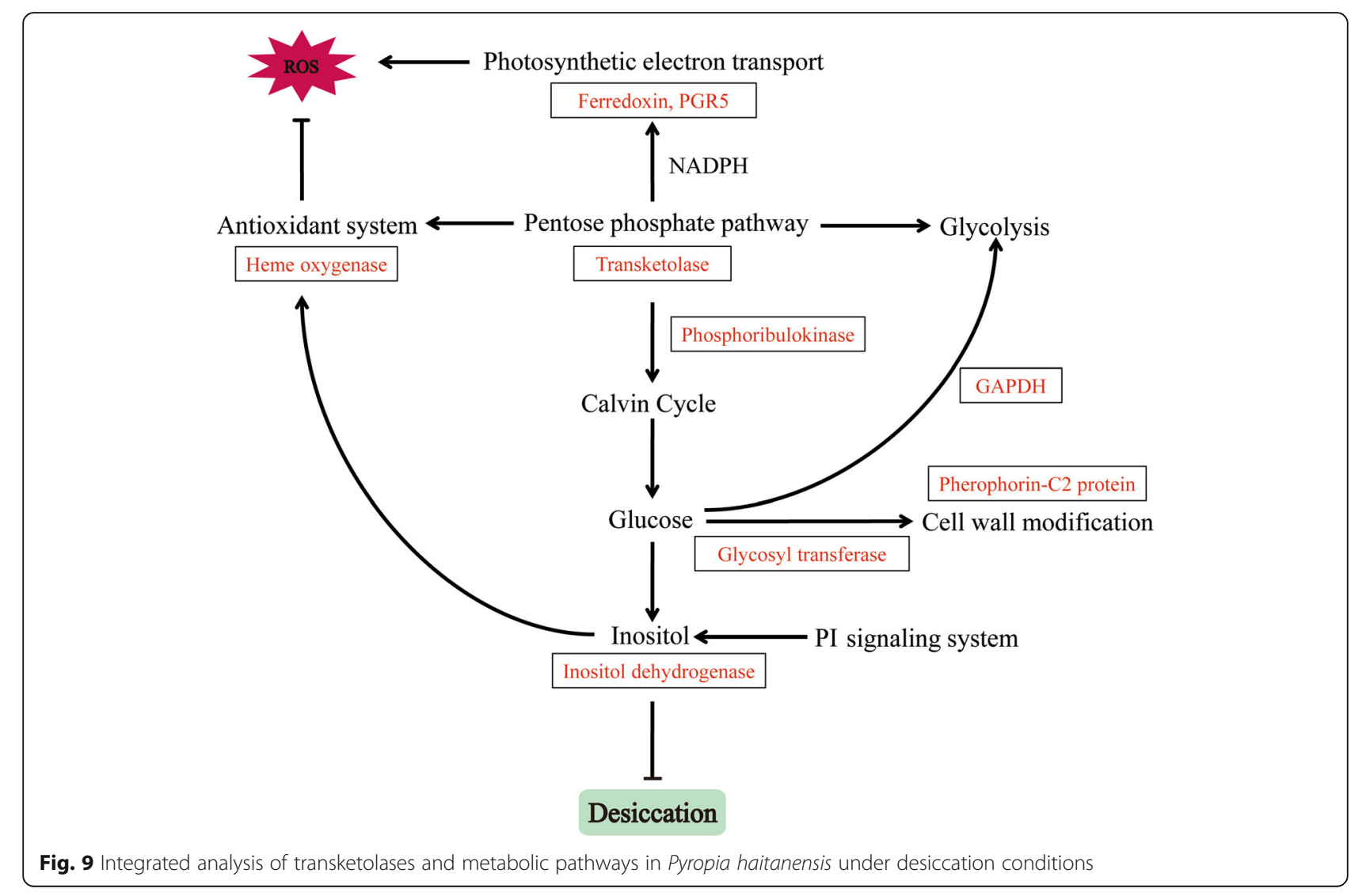




\section{Conclusions}

We conducted an integrated transcriptome and proteome analysis of $P$. haitanensis exposed to desiccation stress. Our data revealed a clear $P$. haitanensis response to desiccation conditions, with a $60 \%$ WL rate representing an important threshold for this response. The P. haitanensis thalli were able to grow normally under mild desiccation conditions; however, a WL rate exceeding 60\% activated desiccation-tolerance mechanisms that mainly affected photosynthetic activities as well as the cell wall and cytoskeleton, the pentose phosphate pathway, and the antioxidant system. Our integrated analysis of the transcriptome, proteome, and transgenic $C$. reinhardtii implied that the pentose phosphate pathway plays a central role in the desiccation tolerance of $P$. haitanensis. This is the first study to elucidate the transcriptomic and proteomic changes in $P$. haitanensis in response to desiccation stress. The data presented herein provide new insights into the molecular mechanism underlying the desiccation tolerance of macroalgae.

\section{Methods}

\section{Materials and stress treatment}

Pyropia haitanensis strain Z-61 was obtained from the Laboratory of Germplasm Improvements and Applications of Pyropia at Jimei University, Fujian, China [63]. Blades were cultured in Provasoli's enriched seawater in a growth chamber set at $21^{\circ} \mathrm{C}$ with a 12-h light: 12 -h dark photoperiod $\left(50 \mu \mathrm{mol}\right.$ photons $\left.\mathrm{m}^{-2} \mathrm{~s}^{-1}\right)$. Provasoli's enriched seawater was refreshed every 3 days. The Z-61 blades that grew to $15 \pm 2 \mathrm{~cm}$ were randomly selected for a stress treatment. Three biological replicates for each sample were analyzed in the subsequent experiments. The following four desiccation levels were set based on water loss: $0 \%$ (control), 30\% (mild desiccation), 60\% (moderate desiccation), and 90\% (severe desiccation). The rehydration (R) treatment involved submerging blades for $2 \mathrm{~h}$ after the water loss reached $90 \%$. The temperature was held constant for the desiccation and rehydration treatments. The water-loss (WL) rate was calculated with the following published equation with some modifications [5]. First, we designed a pre-experiment to estimate the initial water content (IWC) of Z-61 strain. In total, 12 blades which were $15 \pm 2 \mathrm{~cm}$ in length were selected and weighed after removing the surface water with gauze (W0). Then, they were dried in an oven at $60^{\circ} \mathrm{C}$ to a constant weight (Wi). IWC was calculated using the following formula:

$$
\mathrm{IWC}=\sum_{i=1}^{n=12}(W 0-W i) /(W 0 \times 12)
$$

For the desiccation treatment, we first obtained the weight (W0) after drying the surface of blades with gauze. Then, based on the IWC and specific water loss rate (WL), we calculate the actual weight (Wd) according to the following formula:

$$
\mathrm{WL}=(W 0-W d) /(W 0 \times I W C) \times 100 \%
$$

Then, the Z-61 blades were exposed to the air and weighed every $15 \mathrm{~min}$. When Wd was reached, the blades were stored in liquid nitrogen for further RNA and protein extraction.

Chlamydomonas reinhardtii strain "CC-400 cw15 mt+" was provided by Prof. Tse-Min Lee (Institute of Marine Biology, National Sun Yat-sen University), and used to assay the physiological function of candidate genes. Specifically, C. reinhardtii cells were grown in Tris-acetate-phosphate (TAP) medium at $25^{\circ} \mathrm{C}$ with shaking at $100 \mathrm{rpm}$ under $14 \mathrm{~h}: 10 \mathrm{~h}$ light/dark (L:D) photoperiod with cool fluorescent light $(50 \mu \mathrm{mol}$ photons $\mathrm{m}^{-2} \mathrm{~s}^{-1}$ ). For the osmotic stress treatment, cells were cultured until log phase, and then transferred into TAP medium containing $200 \mathrm{mM}$ mannitol for 3 days under the same conditions as the control group. The cell growth rate was calculated using OD values at $750 \mathrm{~nm}$ to measure the ability of cells to resist osmotic stress (Additional file 1: Figure S4) [64].

RNA extraction, de novo assembly, and gene annotation The E.Z.N.A. Plant RNA Kit (OMEGA, Germany) was used to extract total RNA from seaweed samples that underwent desiccation and rehydration treatments. High-quality RNA was used for an RNA-sequencing (RNA-seq) analysis, which was completed with an Illumina HiSeq 2000 system at the Majorbio BioTech Co. Ltd. (Shanghai, China). The details of gene assembly and annotation were previously provided by Xie et al (2013) [65]. Gene expression levels were calculated based on the RPKM (reads per kb per million reads) method [66].

\section{Verification by quantitative real-time PCR}

First-strand cDNA was synthesized from $1 \mu \mathrm{g}$ total RNA with the PrimeScript ${ }^{\text {Ts }}$ RT reagent Kit with gDNA Eraser (TaKaRa, Japan). All cDNA samples were diluted with nuclease-free water to $5 \mathrm{ng} \mu \mathrm{L}^{-1}$ before being analyzed in a quantitative real-time polymerase chain reaction (qRT-PCR) assay, which was performed in 96-well plates with an ABI 7300 Real-time PCR Detection system. The ubiquitin-conjugating enzyme gene $(P h U B C)$ served as a control to normalize target gene expression levels [67]. Details regarding the gene-specific qRT-PCR primers are provided in Additional file 1: Table S1. The qRT-PCR program was as follow: $95^{\circ} \mathrm{C}$ for $30 \mathrm{~s}, 40$ cycles of $95^{\circ} \mathrm{C}$ for $5 \mathrm{~s}$ and $60^{\circ} \mathrm{C}$ for $31 \mathrm{~s}$. The qRT-PCR assay was performed in triplicate for each sample. 


\section{Proteomic analysis}

Previously described methods were used for extracting, digesting, and labeling proteins [15]. The average value of three biological replicates and three technical replicates was calculated to represent the final protein abundances at each time point. Proteins with a 1.2-fold change in abundance between samples $(p$-value $<0.05)$ were determined as DEPs.

\section{Validation of differentially expressed proteins using a multiple reaction monitoring analysis}

Samples were extracted and digested as described and then spiked with $50 \mathrm{fmol} \beta$-galactosidase to normalize the data. Multiple reaction monitoring (MRM) analyses were completed with a QTRAP 5500 mass spectrometer (SCIEX, Framingham, MA, USA) equipped with LC-20 AD nanoHPLC system (Shimadzu, Kyoto, Japan). The generated raw data file was integrated with Skyline software. All the transitions for each peptide were used for quantification unless interference from the matrix was detected. A sample spiked with $\beta$-galactosidase was used for lable-free data normalization. We used MSstats with the linear mixed-effects model, and the $p$ values were adjusted to control the false discovery rate at a cutoff of 0.05 . All the proteins having at least 1.2-fold changes in abundance $(p<0.05)$ were considered significant.

\section{Functional classification and enrichment analysis}

DEPs were functionally classified according to MapMan ontology [68]. An enrichment analysis was conducted with the Singular Enrichment Analysis tool of the agriGO toolkit [69]. The enriched metabolic pathways associated with the responsive proteins were identified based on the information in the Kyoto Encyclopedia of Genes and Genomes pathway database.

\section{Isolation of the transketolase gene and vector construction}

The complete cDNA of transketolase gene of $P$. haitanensis (PhTKL) was cloned using gene-specific primers (Additional file 1: Table S2). The pChlamy_3 vector (Invitrogen, USA) was used to construct the transformation vector. The PCR-amplified PhTKL sequence and the pChlamy_3 vector were digested with $K p n \mathrm{I}$ and $\mathrm{XbaI}$ (TaKaRa, Japan), after which they were ligated to generate the pChlamy-PhTKL recombinant plasmid.

\section{Chlamydomonas reinhardtii nuclear transformation}

Chlamydomonas reinhardtii cells were transformed according to a modified version of an electroporation procedure described by Yamano et al. (2013) [70]. The $C$. reinhardtii cells were cultured until the cell density reached $1 \sim 2 \times 10^{6}$ cells $\mathrm{mL}^{-1} .10 \mathrm{~mL}$ aliquot of cultured cells was collected by centrifugation at $600 \times \mathrm{g}$ for $5 \mathrm{~min}$ and re-suspended in $200 \mu \mathrm{L}$ TAP medium containing 40 $\mathrm{mM}$ sucrose for a final density of $1 \times 10^{8}$ cells $\mathrm{mL}^{-1}$. Then, $2 \mu \mathrm{g}$ pChlamy-PhTKL plasmid was linearized with $\mathrm{KpnI}$ and added to the cell suspension. The cell suspension was placed into an electroporation cuvette (ECM830, USA). Parameters were optimized as three Pps of $300 \mathrm{~V}$ with a $6 \mathrm{~ms}$ pulse length and a $50 \mathrm{~ms}$ pulse interval. After the electroporation, the cell suspension was transferred to $10 \mathrm{~mL}$ TAP medium containing 40 $\mathrm{mM}$ sucrose and incubated under dim light $(1 \sim 2 \mu \mathrm{mol}$ photons $\mathrm{m}^{-2} \mathrm{~s}^{-1}$ ) for $24 \mathrm{~h}$. Transformed colonies were identified after a 3-day growth period on agar-solidified TAP medium containing $10 \mu \mathrm{g} / \mathrm{mL}$ hygromycin. Cell growth was monitored based on the cell counts determined by measuring the optical density at $750 \mathrm{~nm}$ [64].

\section{Statistical analysis}

The qRT-PCR analysis of PhTKL expression was repeated three times. Data were recorded as the means \pm standard deviations. The significance of any differences between the treatment and control values was determined with a one-way ANOVA and the LSD post hoc test in SPSS 12.0 (SPSS Inc., Chicago, IL, USA) $(p<$ 0.05).

\section{Supplementary information}

Supplementary information accompanies this paper at https://doi.org/10. 1186/s12870-019-2076-4

\begin{abstract}
Additional file 1: Table S1. Gene-specific qRT-PCR primers for verifying differentially expressed genes in Pyropia haitanensis. Table S2. Genespecific primers for cloning PhTKL and quantifying its expression. Table S3. Summary of the Pyropia haitanensis transcriptome. Table S4. Important differentially expressed genes in Pyropia haitanensis under desiccation and rehydration conditions. Figure S1. Relative expression of unigenes in Pyropia haitanensis under desiccation conditions as determined by qRTPCR. Figure S2. Comparison of the changes in mRNA levels and protein abundances in Pyropia haitanensis. The relative changes are presented on a log2 scale: (A) $30 \%$ vs $0 \%$, (B) $60 \%$ vs $0 \%$, (C) $90 \%$ vs $0 \%$, and (D) rehydration vs $0 \%$. Different colored spots represent the following results: red, mRNA levels and protein abundances changed significantly; green, only the mRNA levels changed significantly; blue, only the protein abundances changed significantly; black, neither the mRNA levels nor protein abundances changed significantly $(p>0.05)$. Figure S3. Verification of the presence of PhTKL in transgenic Chlamydomonas reinhardtii. Figure S4. Correlation between C. reinhardtii culture $\mathrm{OD}_{750}$ and cell number. The $\mathrm{OD}_{750}$ values of the four cultures used for the experiment were $0.0962 \pm$ $0.0010,0.1544 \pm 0.0008,0.2261 \pm 0.0049$ and $0.3250 \pm 0.0016$ respectively
\end{abstract}

\section{Abbreviations \\ 2-DE: Two-dimensional electrophoresis; DEGs: Differently expressed genes; DEPs: Differently expressed proteins; PBPs: Phycobiliproteins; PCA: Principal component analysis; PhUBC: Ubiquitin conjugating enzyme gene; PSI: Photosystem I; PSII: Photosystem II; qRT-PCR: Quantitative real-time PCR; ROS: Reactive oxygen species; TAP: Tris-acetate-phosphate; TCA: Tricarboxylic acid; TKL: Transketolase; TPS: Trehalose-6-phosphate synthase; WT: Wild-type}

\section{Acknowledgements}

We thank Liwen Bianji, Edanz Group China (www.liwenbianji.cn/ac) for editing the English text of a draft of this manuscript. 


\section{Authors' contributions}

JS, WW, CX and CC conceived and designed the experiment. WW, JS, YL, YX and KX performed the experiments and data analyses. JS, WW, DJ and CX drafted the manuscript. WW, JS and CX revised the manuscript. All the authors read and approved the final manuscript.

\section{Authors' information}

Jianzhi Shi and Wenlei Wang contributed equally to this work.

\section{Funding}

This work was supported by the National Natural Science Foundation of China (Grant No: 41806185), the Natural Science Foundation of Fujian Province, China (Grant Nos. 2018 J05069) and China Agriculture Research System (CARS-50)". These funding bodies have had no role in the design of the study and collection, analysis, and interpretation of data and in writing the manuscript.

\section{Availability of data and materials}

All supporting data are included within the article or in the additional files.

\section{Ethics approval and consent to participate}

Not applicable.

\section{Consent for publication}

Not applicable.

\section{Competing interests}

The authors declare that they have no competing interests.

Received: 31 October 2018 Accepted: 16 October 2019 Published online: 06 November 2019

\section{References}

1. Blouin NA, Brodie JA, Grossman AC, Xu P, Brawley SH. Porphyra: a marine crop shaped by stress. Trends Plant Sci. 2011;16(1):29-37.

2. FAO. Fisheries and aquaculture-fisheries and aquaculture fact sheets. URL (http://www.fao.org/fishery/factsheets/en.) (accessed 2 Aug 2017).

3. Kellogg J, Lila MA. Chemical and in vitro assessment of Alaskan coastal vegetation antioxidant capacity. J Agric Food Chem. 2013;61(46):11025-32.

4. China Fishery Bureau, Fishery Production, China Fishery Statistical Yearbook (in Chinese), Chinese Agriculture Express (2016).

5. Xie J, Xu Y, Ji D, Chen C, Xie C. Physiological response of the antioxidant system in Pyropia haitanensis to desiccation stress (in Chinese). J Fish Sci Chin. 2014;21(2):405-12.

6. Flores-Molina MR, Thomas D, Lovazzano C, Núñez A, Zapata J, Kumar M, Correa JA, Contreras-Porcia L. Desiccation stress in intertidal seaweeds: effects on morphology, antioxidant responses and photosynthetic performance. Aquat Bot. 2014;113:90-9.

7. Qian F, Luo Q, Yang R, Zhu Z, Chen H, Yan X. The littoral red alga Pyropia haitanensis uses rapid accumulation of floridoside as the desiccation acclimation strategy. J Appl Phycol. 2015;27(1):621-32.

8. Challabathula D, Bartels D. Desiccation tolerance in resurrection plants: new insights from transcriptome, proteome and metabolome analysis. Front Plant Sci. 2013:4:482.

9. Wang W, Teng F, Lin Y, Ji D, Xu Y, Chen C, Xie C. Transcriptomic study to understand thermal adaptation in a high temperature-tolerant strain of Pyropia haitanensis. PLoS One. 2018;13(4):e0195842.

10. Wang W, Lin Y, Teng F, Ji D, Xu Y, Chen C, Xie C. Comparative transcriptome analysis between heat-tolerant and sensitive Pyropia haitanensis strains in response to high temperature stress. Algal Res. 2018; 29:104-12.

11. Im S, Lee HN, Jung HS, Yang S, Park EJ, Hwang MS, Jeong WJ, Choi DW. Transcriptome-based identification of the desiccation response genes in marine red algae Pyropia tenera (Rhodophyta) and enhancement of abiotic stress tolerance by PtDRG2 in Chlamydomonas. Mar Biotechnol. 2017;19(3):232-45.

12. Wang L, Mao Y, Kong F, Cao M, Sun P. Genome-wide expression profiles of Pyropia haitanensis in response to osmotic stress by using deep sequencing technology. BMC Genomics. 2015;16(1):1012.

13. López-Cristoffanini C, Zapata J, Gaillard F, Potin P, Correa JA, ContrerasPorcia L. Identification of proteins involved in desiccation tolerance in the red seaweed Pyropia orbicularis (Rhodophyta, Bangiales). Proteomics. 2015; 15(23-24):3954-68.

14. Xu K, Xu Y, Ji D, Xie J, Chen C, Xie C. Proteomic analysis of the economic seaweed Pyropia haitanensis in response to desiccation. Algal Res. 2016;19:198-206.

15. Shi J, Chen Y, Xu Y, Ji D, Chen C, Xie C. Differential proteomic analysis by iTRAQ reveals the mechanism of Pyropia haitanensis responding to high temperature stress. Sci Rep. 2017;7:44734.

16. Lee HN, Kim SH, Han YJ, Im S, Jeong WJ, Park EJ, Hwang MS, Choi DW. PSCYP1 of marine red alga Pyropia seriata (Bangiales, Rhodophyta) confers salt and heat tolerance in Chlamydomonas. J Appl Phycol. 2017;29(1):617-25.

17. Na Y, Lee HN, Wi J, Jeong WJ, Choi DW. PtDRG1, a desiccation response gene from Pyropia tenera (Rhodophyta), exhibits chaperone function and enhances abiotic stress tolerance. Mar Biotechnol. 2018;20(5):584-93.

18. Takahashi S, Murata N. How do environmental stresses accelerate photoinhibition? Trends Plant Sci. 2008;13(4):178-82.

19. Kanady JS, Tsui EY, Day MW, Agapie T. A synthetic model of the Mn3Ca subsite of the oxygen-evolving complex in photosystem II. Science. 2011; 333(6043):733-6.

20. Georgieva K, Röding A, Büchel C. Changes in some thylakoid membrane proteins and pigments upon desiccation of the resurrection plant Haberlea rhodopensis. J Plant Physiol. 2009;166(14):1520-8.

21. Jiang G, Wang Z, Shang H, Yang W, Hu Z, Phillips J, Deng X. Proteome analysis of leaves from the resurrection plant Boea hygrometrica in response to dehydration and rehydration. Planta. 2007;225(6):1405.

22. Kumar M, Kumari P, Reddy CRK, Jha B. Salinity and desiccation induced oxidative stress acclimation in seaweeds. In: Advances in Botanical Research. Amsterdam: Elsevier Academic Press; 2014;71:91-123.

23. Gao S, Niu J, Chen W, Wang G, Xie X, Pan G, Gu W, Zhu D. The physiological links of the increased photosystem II activity in moderately desiccated Porphyra haitanensis (Bangiales, Rhodophyta) to the cyclic electron flow during desiccation and re-hydration. Photosynthesis Res. 2013; 116(1):45-54.

24. Gao S, Wang G. The enhancement of cyclic electron flow around photosystem I improves the recovery of severely desiccated Porphyra yezoensis (Bangiales, Rhodophyta). J Exp Bot. 2012;63(12):4349-58.

25. DalCorso G, Pesaresi P, Masiero S, Aseeva E, Schünemann D, Finazzi G, Joliot P, Barbato R, Leister D. A complex containing PGRL1 and PGR5 is involved in the switch between linear and cyclic electron flow in Arabidopsis. Cell. 2008;132(2):273-85.

26. Suorsa M, Järvi S, Grieco M, Nurmi M, Pietrzykowska M, Rantala M, Kangasjärvi S, Paakkarinen V, Tikkanen M, Jansson S, Aro EM. Proton gradient regulation5 is essential for proper acclimation of Arabidopsis photosystem I to naturally and artificially fluctuating light conditions. Plant Cell. 2012;24(7):2934-48

27. Long TA, Okegawa Y, Shikanai T, Schmidt GW, Covert SF. Conserved role of proton gradient regulation 5 in the regulation of PSI cyclic electron transport. Planta. 2008;228(6):907.

28. Sasidharan $R$, Voesenek LA, Pierik R. Cell wall modifying proteins mediate plant acclimatization to biotic and abiotic stresses. Crit Rev Plant Sci. 2011; 30(6):548-62.

29. Holzinger A, Herburger K, Kaplan F, Lewis LA. Desiccation tolerance in the chlorophyte green alga Ulva compressa: does cell wall architecture contribute to ecological success? Planta. 2015;242(2):477-92.

30. Herburger K, Xin A, Holzinger A. Homogalacturonan accumulation in cell walls of the green alga Zygnema sp. (Charophyta) increases desiccation resistance. Frontiers. Plant Sci. 2019;10:540.

31. Wang W, Xu Y, Chen T, Xing L, Xu K, Ji D, Chen C, Xie C. Regulatory mechanisms underlying the maintenance of homeostasis in Pyropia haitanensis under hypersaline stress conditions. Sci Total Environ. 2019; 662:168-79.

32. Osakabe Y, Yamaguchi-Shinozaki K, Shinozaki K, Tran LSP. Sensing the environment: key roles of membrane-localized kinases in plant perception and response to abiotic stress. J Exp Bot. 2013;64(2):445-58.

33. Lindner $H$, Müller LM, Boisson-Dernier A, Grossniklaus U. CrRLK1L receptorlike kinases: not just another brick in the wall. Curr Opin Plant Biol. 2012; 15(6):659-69.

34. de Carvalho RC, da Silva AB, Soares R, Almeida AM, Coelho AV, da Silva JM, Branquinho C. Differential proteomics of dehydration and rehydration in bryophytes: evidence towards a common desiccation tolerance mechanism. Plant Cell Environ. 2014;37(7):1499-515. 
35. Wang XQ, Yang PF, Liu Z, Liu WZ, Hu Y, Chen H, et al. Exploring the mechanism of Physcomitrella patens desiccation tolerance through a proteomic strategy. Plant Physiol. 2009;149(4):1739-50.

36. Holzinger A, Lütz C, Karsten U. Desiccation stress causes structural and ultrastructural alterations in the aeroterrestrial green alga Klebsormidium crenulatum (Klebsormidiophyceae, Streptophyta) isolated from an alpine soil crust 1. J Phycol. 2011;47(3):591-602.

37. Holzinger $\mathrm{A}$, Karsten $U$. Desiccation stress and tolerance in green algae: consequences for ultrastructure, physiological and molecular mechanisms. Frontiers Plant Sci. 2013;4:327.

38. Garg AK, Kim JK, Owens TG, Ranwala AP, Choi YD, Kochian LV, Wu RJ. Trehalose accumulation in rice plants confers high tolerance levels to different abiotic stresses. P Natl Acad Sci. 2002:99(25):15898-903.

39. Shi J, Xu Y, Ji D, Chen C, Xie C. Cloning and expression analysis of trehalose6-phosphate synthase (TPS) family genes from Pyropia haitanensis (in Chinese). J Fish China. 2015;39(4):485-95.

40. Zentella R, Mascorro-Gallardo JO, Van Dijck P, Folch-Mallol J, Bonini B, Van Vaeck C, et al. Selaginella lepidophylla trehalose-6-phosphate synthase complements growth and stress-tolerance defects in a yeasttps 1 mutant. Plant Physiol. 1999;119(4):1473-82.

41. Fierro C, López-Cristoffanini C, Meynard A, Lovazzano C, Castañeda F, Guajardo E, Contreras-Porcia L. Expression profile of desiccation tolerance factors in intertidal seaweed species during the tidal cycle. Planta. 2017; 245(6):1149-64

42. Araújo WL, Tohge T, Ishizaki K, Leaver CJ, Fernie AR. Protein degradation-an alternative respiratory substrate for stressed plants. Trends Plant Sci. 2011; 16(9):489-98.

43. Fan $M$, Sun $X, X u$, Liao Z, Li Y, Wang J, Fan Y, Cui D, Li P, Miao Z. Integration of deep transcriptome and proteome analyses of salicylic acid regulation high temperature stress in Ulva prolifera. Sci Rep. 2017:7(1):11052.

44. Ji D, Li B, Xu Y, et al. Cloning and quantitative analysis of five heat shock protein 70 genes from Pyropia haitanensis. J Appl Phycol. 2015; 27(1):499-509

45. Wang W, Chang J, Zheng H, Ji D, Xu Y, Chen C, Xie C. Full-length transcriptome sequences obtained by a combination of sequencing platforms applied to heat shock proteins and polyunsaturated fatty acids biosynthesis in Pyropia haitanensis. J Appl Phycol. 2019;31:1483-92.

46. Wang W, Vinocur B, Shoseyov O, Altman A. Role of plant heat-shock proteins and molecular chaperones in the abiotic stress response. Trends Plant Sci. 2004;9(5):244-52.

47. Georgieva K, Dagnon S, Gesheva E, Bojilov D, Mihailova G, Doncheva S. Antioxidant defense during desiccation of the resurrection plant Haberlea rhodopensis. Plant Physiol Bioch. 2017;114:51-9.

48. Pan L, Meng C, Wang J, et al. Integrated omics data of two annual ryegrass (Lolium multiflorum L.) genotypes reveals core metabolic processes under drought stress. BMC Plant Biol. 2018;18(1):26.

49. Holzinger A, Kaplan F, Blaas K, Zechmann B, Komsic-Buchmann K, Becker B. Transcriptomics of desiccation tolerance in the streptophyte green alga Klebsormidium reveal a land plant-like defense reaction. PLoS One. 2014 9(10):e110630

50. Rippin $\mathrm{M}$, Becker $\mathrm{B}$, Holzinger $\mathrm{A}$. Enhanced desiccation tolerance in mature cultures of the streptophytic green alga Zygnema circumcarinatum revealed by transcriptomics. Plant Cell Physiol. 2017;58(12):2067-84.

51. Ji D, Xu Y, Xiao H, Chen C, Xu K, Xie C. Superoxide dismutase genes in Pyropia haitanensis: molecular cloning, characterization and mRNA expression. Acta Oceanol Sin. 2016;35(6):101-11.

52. Reape TJ, Molony EM, McCabe PF. Programmed cell death in plants: distinguishing between different modes. J Exp Bot. 2008;59(3):435-44.

53. Zadražnik T, Hollung K, Egge-Jacobsen W, Meglič V, Šuštar-Vozlič J. Differential proteomic analysis of drought stress response in leaves of common bean (Phaseolus vulgaris L.). J. Proteomics. 2013;78:254-72.

54. Plaxton WC. The organization and regulation of plant glycolysis. Annu Rev Plant Biol. 1996;47(1):185-214.

55. Fernie AR, Carrari F, Sweetlove $\sqcup$. Respiratory metabolism: glycolysis, the TCA cycle and mitochondrial electron transport. Curr Opin Plant Biol. 2004;7(3):254-61.

56. Stincone A, Prigione A, Cramer T, Wamelink MM, Campbell K, Cheung E, OlinSandoval V, Grüning NM, Krüger A, Alam MT, Keller MA, Breitenbach M, Brindle KM, Rabinowitz JD, Ralser M. The return of metabolism: biochemistry and physiology of the pentose phosphate pathway. Biol Rev. 2015;90(3):927-63.

57. Bernacchia G, Schwall G, Lottspeich F, Salamini F, Bartels D. The transketolase gene family of the resurrection plant Craterostigma
Plantagineum: differential expression during the rehydration phase. EMBO J. 1995:14(3):610-8.

58. Huan L, Xie X, Zheng Z, Sun F, Wu S, Li M, Gao S, Gu W, Wang G. Positive correlation between PSI response and oxidative pentose phosphate pathway activity during salt stress in an intertidal macroalga. Plant Cell Physiol. 2014;55(8):1395-403.

59. Michels AK, Wedel N, Kroth PG. Diatom plastids possess a phosphoribulokinase with an altered regulation and no oxidative pentose phosphate pathway. Plant Physiol. 2005;137(3):911-20.

60. Egelund J, Skjøt M, Geshi N, Ulvskov P, Petersen BL. A complementary bioinformatics approach to identify potential plant cell wall glycosyltransferase-encoding genes. Plant Physiol. 2004;136(1):2609-20.

61. Bolouri-Moghaddam MR, Le Roy K, Xiang L, Rolland F, Van den Ende W. Sugar signalling and antioxidant network connections in plant cells. FEBS J. 2010;277(9):2022-37.

62. Yannarelli GG, Noriega GO, Batlle A, Tomaro ML. Heme oxygenase upregulation in ultraviolet- $B$ irradiated soybean plants involves reactive oxygen species. Planta. 2006;224(5):1154-62.

63. Chen C, Ji D, Xie C, Xu Y, Liang Y, Zhen Y, Shi X, Wang F, Zhao L. Preliminary study on selecting the high temperature resistance strains and economic traits of Porphyra haitanensis (in Chinese). Acta Oceanol Sin. 2008;30:100-6.

64. Kumar A, Falcao VR, Sayre RT. Evaluating nuclear transgene expression systems in Chlamydomonas reinhardtii. Algal Res. 2013;2(4):321-32.

65. Xie C, Li B, Xu Y, Chen C. Characterization of the global transcriptome for Pyropia haitanensis (Bangiales, Rhodophyta) and development of cSSR markers. BMC Genomics. 2013;14(1):107.

66. Mortazavi A, Williams BA, McCue K, Schaeffer L, Wold B. Mapping and quantifying mammalian transcriptomes by RNA-Seq. Nat Methods. 2008;5(7):621-8.

67. Li B, Chen C, Xu Y, Ji D, Xie C. Validation of housekeeping genes as internal controls for studying the gene expression in Pyropia haitanensis (Bangiales, Rhodophyta) by quantitative real-time PCR (in Chinese). Acta Oceanol Sin. 2014;33:152-9.

68. Usadel B, Poree F, Nagel A, Lohse M, Czedik-Eysenberg A, Stitt M. A guide to using MapMan to visualize and compare Omics data in plants: a case study in the crop species, Maize. Plant Cell Environ. 2009:32(9):1211-29.

69. Du Z, Zhou X, Ling Y, Zhang Z, Su Z. agriGO: a GO analysis toolkit for the agricultural community. Nucleic Acids Res. 2010;38(Web Server issue):W64-70.

70. Yamano $\mathrm{T}$, Iguchi $\mathrm{H}$, Fukuzawa H. Rapid transformation of Chlamydomonas reinhardtii without cell-wall removal. J Biosci Bioeng. 2013;115(6):691-4.

\section{Publisher's Note}

Springer Nature remains neutral with regard to jurisdictional claims in published maps and institutional affiliations.

Ready to submit your research? Choose BMC and benefit from:

- fast, convenient online submission

- thorough peer review by experienced researchers in your field

- rapid publication on acceptance

- support for research data, including large and complex data types

- gold Open Access which fosters wider collaboration and increased citations

- maximum visibility for your research: over $100 \mathrm{M}$ website views per year

At $\mathrm{BMC}$, research is always in progress.

Learn more biomedcentral.com/submissions 